\title{
Calculated CIM Power Distributions for Coil Design
}

by

B. J. Hardy

Westinghouse Savannah River Company

Savannah River Site

Aiken, South Carolina 29808

This paper was prepared in connection with work done under the above contract number with the U.S.

Department of Energy. By acceptance of this paper, the publisher and/or recipient acknowledges the U. S. Government's right to retain a nonexclusive, royalty-free license in and to any copyright covering this paper, along with the right to reproduce and to authorize others to reproduce all or part of the copyrighted paper. 


\section{DISCLAIMER}

This report was prepared as an account of work sponsored by an agency of the United States Government. Neither the United States Government nor any agency thereof, nor any of their employees, makes any warranty, express or implied, or assumes any legal liability or responsibility for the accuracy, completeness, or usefulness of any information, apparatus, product, or process disclosed, or represents that its use would not infringe privately owned rights. Reference herein to any specific commercial product, process, or service by trade name, trademark, manufacturer, or otherwise does not necessarily constitute or imply its endorsement, recommendation, or favoring by the United States Government or any agency thereof. The views and opinions of authors expressed herein do not necessarily state or reflect those of the United States Government or any agency thereof.

This report has been reproduced directly from the best available copy.

Available to DOE and DOE contractors from the Office of Scientific and Technical Information, P.O. Box 62, Oak Ridge, TN 37831; prices available from (615) 576-8401.

Available to the public from the National Technical Information Service, U.S. Department of Commerce, 5285 Port Royal Road, Springfield, VA 22161. 


\section{DISCLAIMER}

Portions of this document may be illegible in electronic image products. Images are produced from the best available original document. 
WSRC-TR-98-00455, Rev. 0

Keywords: Am/Cm,

Power Distribution, Induction Heating, Coil Design

Retention Period: Permanent

\section{CALCULATED CIM POWER DISTRIBUTIONS FOR COIL DESIGN}

December 23, 1998

Bruce J. Hardy

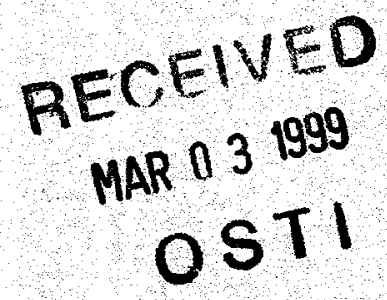

UNCLASSIFIED

DOES NOT CONTAN

UNCLLASSIFIED CONIROLIED

NUCLEAR WFORMATION

ADC 8

REVIEWING

OfFICIAL

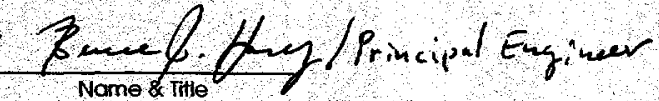

DATE

$$
1 / 2 / 99
$$

Westinghouse Savannah River Company

Savannah River Technology Center

Alken, SC 29808

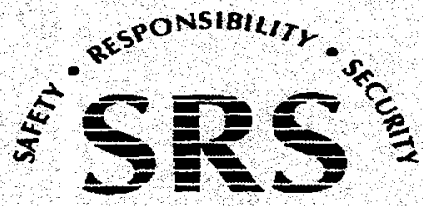




\section{DOCUMENT APPROVAL}

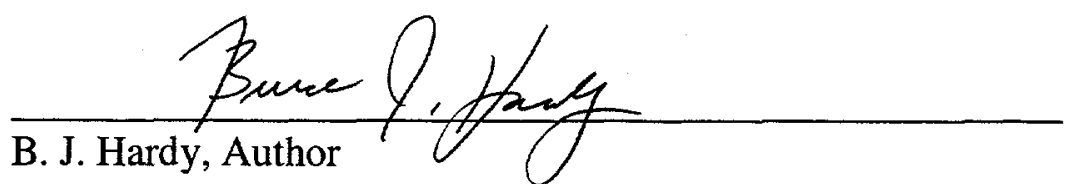
Immobilization Technology Section / SRTC
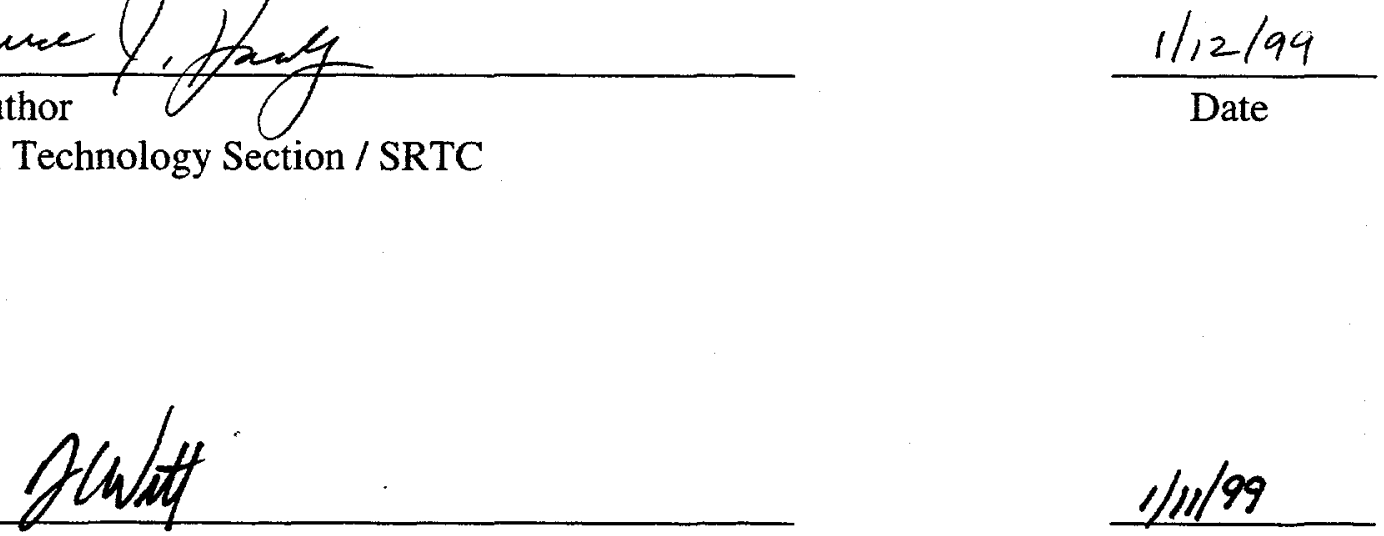

D. C. Witt, Technical Reviewer

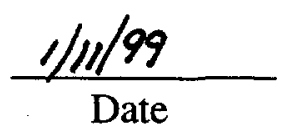

Immobilization Technology Section / SRTC

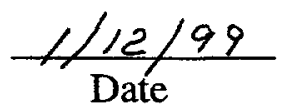

L. F. Landon, Level 4 Manager

Date

Immobilization Technology Section / SRTC

ENotaltophute

E. W. Holtzscheiter, Level 3 Mgr

$\frac{1 / 12 / 99}{\text { Date }}$

Immobilization Technology Section / SRTC

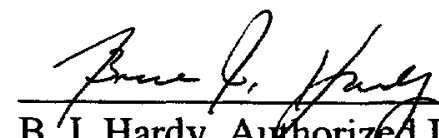

B.J. Hardy, Authorized Derivative Classifier

$1 / 12 / 99$

Date

Immobilization Technology Section / SRTC 


\section{TABLE OF CONTENTS}

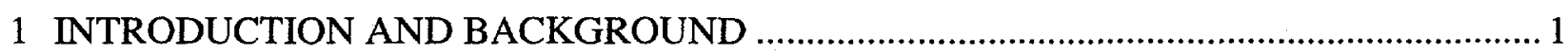

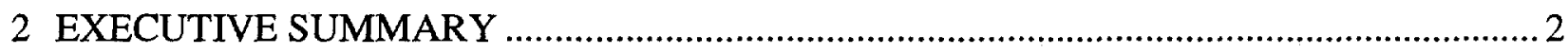

3 MODEL DESCRIPTION



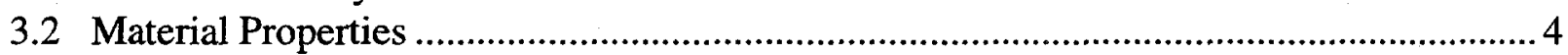

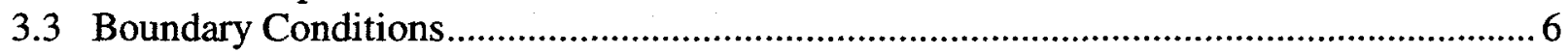

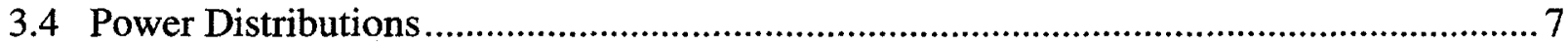

4 RESULTS

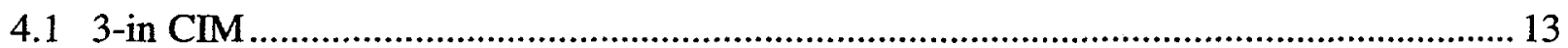

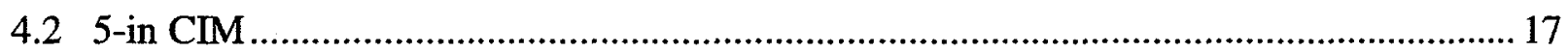

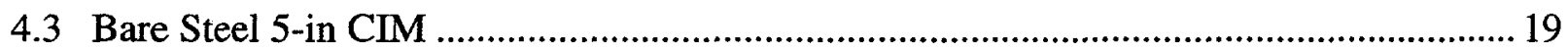

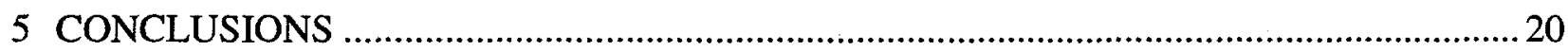



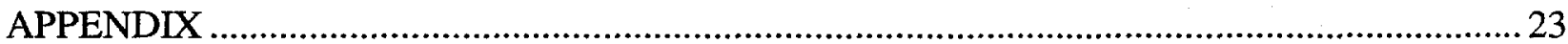

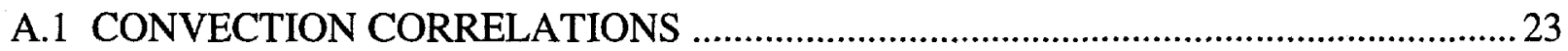






\section{INTRODUCTION AND BACKGROUND}

Excessive bed expansion and material expulsion have occurred during experiments with the 3inch diameter Cylindrical Induction Melter (CIM). Both events were attributed in part to the high power density in the bottom of the melter and the correspondingly high temperatures there. It is believed that the high temperatures resulted in the generation of gasses at the bottom of the bed which could not escape. The gasses released during heating and the response of the bed to gas evolution depend upon the composition of the bed. For bed compositions used in the $\mathrm{Am} / \mathrm{Cm}$ melter, the type of gas generated has the following temperature dependence:

1. At temperatures near $100^{\circ} \mathrm{C}$, water vapor is generated from the drying of the slurry.

2. In the range of temperatures from $100^{\circ} \mathrm{C}$ to $150^{\circ} \mathrm{C}, \mathrm{H}_{2} \mathrm{O}$ vapor is generated from thermal decomposition of the waters of hydration of the oxalate.

3. In the temperature range from $200^{\circ} \mathrm{C}$ to $800^{\circ} \mathrm{C}$, the majority of gas evolution is $\mathrm{CO}$ and $\mathrm{CO}_{2}$ released as the oxalates undergo thermal decomposition.

4. Finally, at temperatures above $900^{\circ} \mathrm{C}$, the reduction of Ce from the feed results in the release of $\mathrm{O}_{2}$.

The induction coil configuration of the original 3-in. CIM places the highest temperature at the bottom of the melter. Hence, gasses were initially generated in the lower portion of the bed as the melter temperature was increased. If the bed consists of a mixture of glass formers and precipitate, under the right conditions water vapor generated at temperatures near $100^{\circ} \mathrm{C}$ may become trapped due to the rheology of the bed. However, at elevated temperatures the bed retains a powder-like structure, which permits release of gasses generated at higher temperatures. If the bed consists of precipitate and SrABS cullet, gasses generated at lower temperatures can be released. But at temperatures (above $900^{\circ} \mathrm{C}$ ) the cullet will begin to soften and will trap gasses, especially $\mathrm{O}_{2}$ generated by $\mathrm{Ce}$ reduction which occurs at temperatures in the $1100^{\circ} \mathrm{C}$ range.

If temperatures are highest near the top of the bed, experimental evidence suggests that the gasses can be successfully released without becoming trapped ${ }^{1,2}$. Hence, it is believed that shaping the power distribution in the Pt/Rh melter vessel to produce higher temperatures near the top of the bed will reduce the amount of bed expansion and will preclude material expulsion. Power shaping can be accomplished through vendor modification of the induction coils.

However, it is essential that detailed design input be provided. It should be noted that the vendor need not reproduce the target power distribution exactly. In fact, it may be impossible to exactly reproduce the target distribution with the induction coils. The target distribution is to serve as a guide for coil design.

The power density in the Pt/Rh vessel is but one component of the energy balance on the system. To estimate the temperature profile in the bed, the entire energy balance, which includes losses, as well as the source terms, must be used. Therefore, the relationship between the power density distributions and the temperature profiles, for both the 3-in. and the 5-in. CIM's, were based on a numerical model that solved the energy balance equations. Calculations performed in this document include a number of approximations, are scoping in nature and are directed at guiding coil design. 


\section{EXECUTIVE SUMMARY}

Experimental evidence suggests that bed expansion and material expulsion may be mitigated by shaping the axial temperature distribution of the bed to place the highest temperatures at the top of the bed. The temperature distribution in the Cylindrical Induction Melter (CIM) can be controlled through the configuration of the induction coils. Modification of the induction coil configuration changes the power distribution and thus, the temperature distribution in the $\mathrm{Pt} / \mathrm{Rh}$ vessel.

In order to provide design data to the induction coil vendor, a thermal model was developed which related the power and temperature distributions for the CIM. The model was applied to both the 3-in. and 5-in. diameter CIM's and was based on the MSC/THERMAL ${ }^{\circledR}$ multipurpose heat conduction and thermal radiation software ${ }^{3}$. The CIM was modeled as a steady-state 2dimensional (radial and axial) body of rotation. Fixed temperature, convection and radiation boundary conditions were applied to the model. Material properties were incorporated at appropriate geometric locations. The gradual heat-up of the melter $\left(\sim 4^{\circ} \mathrm{C} / \mathrm{min}\right)$ was approximated as a steady process in the model. The models were applied at the point during heat-up when the maximum bed temperature is above $1350^{\circ} \mathrm{C}$ and the CIM is filled with dried precipitate and cullet. That is, near the state at which bed expansion due to Ce reduction was experimentally observed. To assess temperature profiles when the bed collapsed, models were also applied to 3 and 5-in. CIM's that contained a pool of glass which had a maximum temperature in excess of $1400^{\circ} \mathrm{C}$. A model was developed for an empty, bare stainless steel 5-in. CIM that was sent to Ameritherm, Inc. of Scottsville, NY to provide data for coil design.

A model for the original coil configuration of the 3-in. CIM was developed for the purpose of comparison with data. The power distribution and efficiency were adjusted until the temperature distribution predicted by the model matched available data. Although the relationship between temperature and power distributions is not unique, coil spacing on the CIM supported the assumed power distribution. The power distribution was then modified to place the maximum temperature near the top of the bed and to give a decrease in temperature as the bottom of the melter is approached. When the modified power distribution was applied to the glass pool at the same total power used for the bed, it was found that the pool temperature was too low for pouring. Sufficiently high pool temperatures were obtained by raising the total power, but because the power distribution was shifted upwards, the wall temperature midway between the top and bottom of the melter became unacceptably high, nearly $1800^{\circ} \mathrm{C}$. The model therefore suggested that the power distribution for the 3-in. CIM will need to be modified when the bed of cullet and precipitate collapses to a pool. The required shift in the power distribution might be most easily accomplished by utilizing an independent coil about the tapered bottom of the melter.

A model was then developed for the 5-in. CIM. As for the 3-in. CIM, the power distribution was adjusted until the maximum temperature was placed near the top of the bed and the temperatures decreased as the bottom of the vessel is approached. To examine the effect on the temperature profile when the bed collapsed to a pool, the power distribution obtained for the bed was applied to a model for a glass pool in the 5-in, CIM. For the pool model, the power distribution was fixed and the total power was increased until an acceptable pool temperature was reached. For 
the 5-in. CIM, the maximum wall temperature was not as high as that required to maintain an acceptable pool temperature for the 3-in. CIM. Although the wall temperature was marginally acceptable, the results from the model indicated that it would be advisable to have the ability to shift the power distribution after the bed has collapsed. As for the 3-in. CIM, a shift in the power distribution would most easily be accomplished by locating an independent coil about the tapered base of the melter.

Ameritherm, Inc. was supplied with an uninsulated 5-in. CIM fabricated from 304L stainless steel to use as a test workpiece for coil design. If the $304 \mathrm{~L}$ vessel had the same power distribution as that for the 5-in. Pt/Rh CIM, modeled above, it would not be expected to have the same temperature distribution because it is uninsulated and empty. However, it is tacitly assumed that the $304 \mathrm{~L} \mathrm{CIM}$ couples inductively in the same way as a $\mathrm{Pt} / \mathrm{Rh}$ alloy vessel of the same dimensions. The assumption implies that for the same coil configuration, the same power densities are produced in both the $\mathrm{Pt} / \mathrm{Rh}$ vessel and the $304 \mathrm{~L}$ vessel. While Ameritherm could not accurately estimate the power distribution for a given coil geometry, measurements of the melter surface temperature could easily be made. Therefore, the temperature profile corresponding to the power distribution of the 5-in. Pt/Rh CIM was calculated for the empty, uninsulated 5-in 304L CIM. By adjusting the coil geometry to achieve the calculated temperature distribution, the target power distribution obtained for the 5-in. Pt/Rh CIM could be approached.

\section{MODEL DESCRIPTION}

The MSC/THERMAL ${ }^{\circledR}$ multipurpose heat conduction and thermal radiation software ${ }^{3}$ was used to numerically model heat transfer in both the 3-in. and 5-in. diameter CIM's. The gradual heatup of the melter $\left(-4^{\circ} \mathrm{C} / \mathrm{min}\right)$ was approximated as a steady process in the model. Local power densities in the $\mathrm{Pt} / \mathrm{Rh}$ shell were input as volumetric heat sources. Convection and thermal radiation boundary conditions were applied to appropriate surfaces. Because MSC/THERMAL does not explicitly calculate fluid convection, convective heat transfer correlations were utilized in the model. Material constitutive properties were applied at their corresponding geometric locations.

The models were applied to the 3 and 5-in. CIM's at the point during heat-up when the maximum bed temperature is above $1350^{\circ} \mathrm{C}$ and the vessel is filled with dried precipitate and cullet. That is, near the state at which bed expansion due to Ce reduction was experimentally observed. To assess temperature profiles when the bed collapsed, models were also applied to 3 and 5-in. CIM's that contained a pool of glass which had a maximum temperature in excess of $1400^{\circ} \mathrm{C}$. In addition, a model was developed for an empty, bare stainless steel 5-in. CIM that was sent to Ameritherm, Inc. of Scottsville, NY to provide data for coil design.

\subsection{Model Geometry}

The 3 and 5-in. CIM's were assumed to be axisymmetric and were thus modeled as bodies of rotation in half-symmetry. By virtue of the geometry, the model had 2-dimesionsional (radial and axial) dependence. Figures 1 and 2 show the wireframe geometry for the 3 and 5-in. CIM models, respectively. 


\subsection{Material Properties}

The constitutive properties of the materials in the CMM models are listed in Table 1. Due to the paucity of available data, much less temperature dependent data, the properties for most materials are very rough estimates. Errors in the properties of the cullet and precipitate bed are compounded by changes in bed consistency and wall contact that occur as the melter temperature is increased. Monochromatic emissivities were assumed to be wavelength and temperature independent, i.e. gray body radiation was assumed. Emissivities marked with * were taken from materials having similar physical characteristics to those used in the melter.

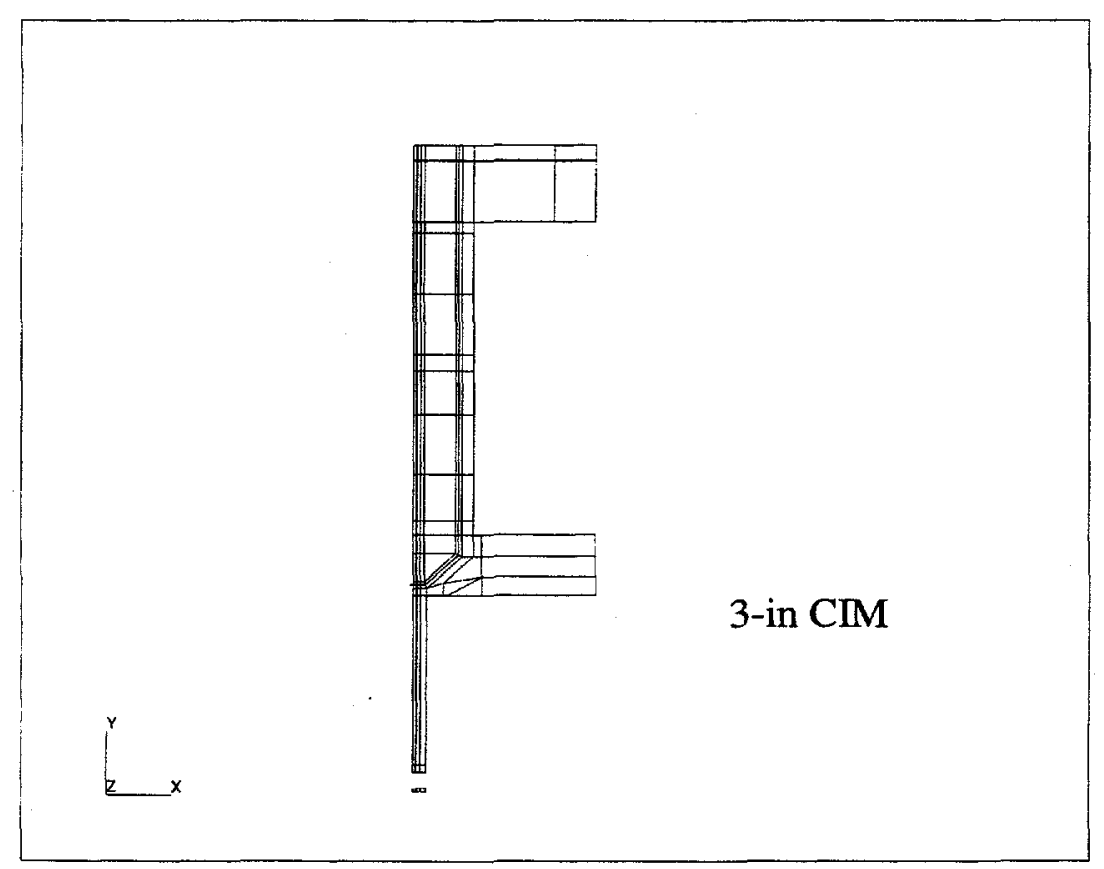

Figure 1. Wireframe for 3-in CIM. 


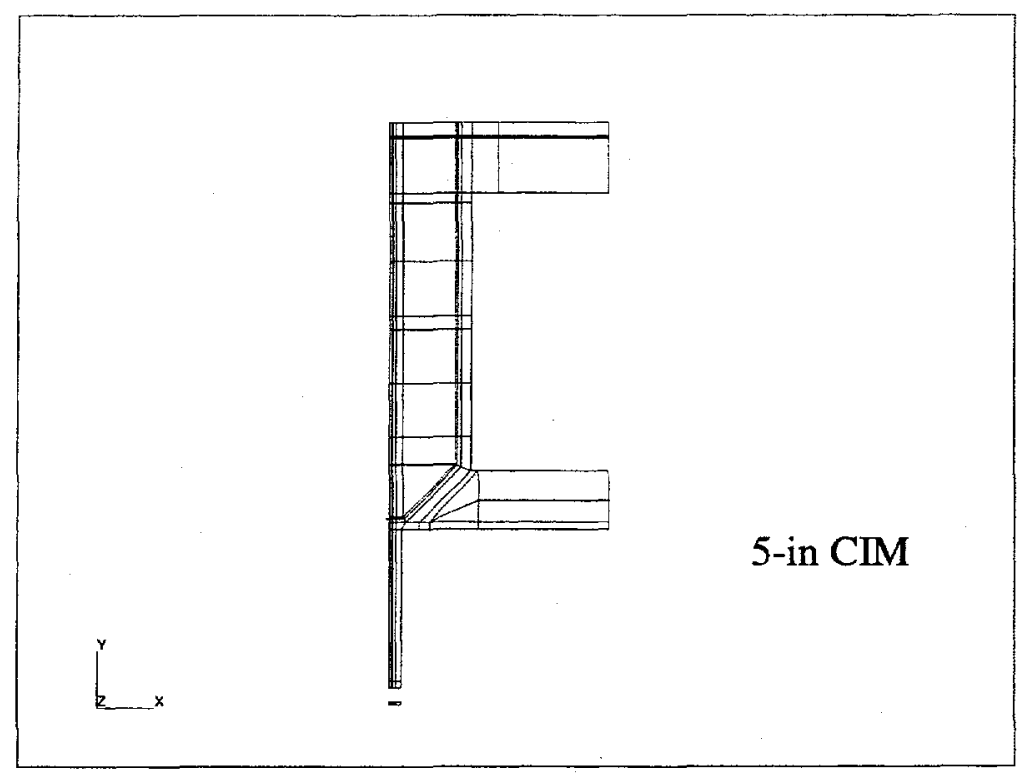

Figure 2. Wireframe for 5-in CIM.

TABLE 1

Material Constitutive Properties

\begin{tabular}{|l|l|l|l|l|}
\hline \multicolumn{1}{|c|}{ Material } & $\begin{array}{c}\text { Thermal Cond. } \\
\left(\mathbf{W} / \mathbf{m}^{\circ} \mathbf{C}\right)\end{array}$ & \multicolumn{1}{|c|}{$\begin{array}{c}\text { Density } \\
\left(\mathbf{k g} / \mathbf{m}^{3}\right)\end{array}$} & $\begin{array}{c}\text { Specific Heat } \\
\left(\mathbf{J} / \mathbf{k g}^{\circ} \mathbf{C}\right)\end{array}$ & Emissivity \\
\hline Air at 500 & 0.058 & 0.44 & 1098. & NA \\
$80 / 20$ PURh Alloy & $72.0^{\mathrm{a}}$ & 18720. & $129 .{ }^{\mathrm{b}}$ & $0.2^{*}$ \\
Zirconia Felt (ZYF) (1) & 0.25 & 240 & 1047 & NA \\
Zircar Refractory (ALC) (1) & 0.20 & 240. & 1047. & $0.4^{*}$ \\
Pyro Putty or Fyre Putty (2) & $0.22^{\mathrm{c}}$ & 2160. & 1000. & NA \\
Cast Refractory (3) & 0.55 & 1440. & 1000. & $0.4^{*}$ \\
Glass Cullet \& Precipitate & $0.89^{\mathrm{d}}$ & $760^{\mathrm{e}}$ & 774. & $0.9^{*}$ \\
Liquid SrABS50 Glass & 4.19 & $3800 .{ }^{\mathrm{f}}$ & 774. & $0.9^{*}$ \\
SG70 Machinable Refr. (4) & $0.62 @ 400^{\circ} \mathrm{C}$ & 2000. & 920. & $0.9^{*}$ \\
SG50 Machinable Refr. (4) & $0.59 @ 400^{\circ} \mathrm{C}$ & 1900. & 920. & $0.9^{*}$ \\
304L Stainless Steel & 16.27 & 8030. & 591.94 & 0.65 \\
\hline
\end{tabular}

1 Zircar Products, Inc., P.O. Box 458, Florida, NY 10921-0458

2 The Carborundum Co., Fiber Division, P.O. Box 808, Niagra Falls, NY 14302-0808

3 A. P. Green, Industres, Inc., Mexico, MO 65265 .

4 Rath Performance Fibers, Inc., Wilmington, DE 19810

a from 60/40 Pt/Rh data

b from Pt data at room temperature

c for Carborundum Fyre Putty ${ }^{\circledR}$

d loosely based on estimated $80 \%$ porosity with air, the actual value is probably lower

e estimated from SrABS glass with $80 \%$ volume reduction from bed \& neglecting mass lost during decomposition

f glass below $800^{\circ} \mathrm{C}$

$\mathrm{g}$ room temperature property 
Both the upper and lower refractories for the 3-in. CIM were fabricated from cast refractory, while for the 5-in. CIM the upper refractory was SG70 machinable material and the lower refractory was SG50 machinable material. 304L was used to fabricate bare stainless steel vessel supplied to Ameritherm for testing of coil designs.

\subsection{Boundary Conditions}

External Boundary Conditions

External boundary conditions are those applied to the outer surfaces of the melter and drain tube insulation.

\section{Convection}

Natural convection boundary conditions were applied to the external surfaces of the model. Nusselt number correlations, invoked in the MSC/THERMAL software, were use to calculate the heat transfer coefficients. The correlations accounted for the orientation, temperatures and dimensions of the sides to which they were applied. All external natural convection was assumed to be relative to an ambient temperature of $30^{\circ} \mathrm{C}$. The correlations used in the model are described in Section A.1 of the Appendix. Temperature dependent properties used in the convection correlations were input via the template.dat.apnd file, shown in Section A.2 of the Appendix.

\section{Thermal Radiation}

Thermal radiation to an ambient temperature of $30^{\circ} \mathrm{C}$ was applied to all external surfaces. The MSC/THERMAL software calculated viewfactors for the surfaces and utilized emissivity data from the template.dat.apnd file listed in Table A.1 of the Appendix.

\section{Fixed Temperatures}

The induction coils are water cooled and maintained at a temperature of approximately $30^{\circ} \mathrm{C}$. For simplicity, it was assumed that the coils contacted the outer surface of the refractory along the side of the melter. For the 3 and 5-in. CIM's, the coils are embedded in the lower refractory material. The coils are also embedded in the top refractory block of the 5-in. CIM. Fixed temperatures of $30^{\circ} \mathrm{C}$ were applied to the outer refractory surface and within the top/bottom refractory material at intervals that approximated the actual coil location.

\section{Drain Tube Annulus Boundary Conditions}

Drain tube annulus boundary conditions are those applied to surfaces that bound the annulus formed by the $\mathrm{Pt} / \mathrm{Rh}$ drain tube and the refractory tube, which acts as a thermal radiation shield. Drain tube annulus boundary conditions are also applied to the bottom of the melter, which forms the upper boundary of the drain tube annulus.

\section{Convection}

Air is directed at the tip of the drain tube to maintain a plug of frozen glass during operation. However, it is believed that some of the air travels into the annular air space of the drain tube assembly. In the model, natural convection was assumed to occur over the full length of the drain tube and was modeled with a Nusselt number correlation. The convection heat transfer coefficient for the drain tube annulus was thus approximated as 
$\mathrm{h}=\overline{\mathrm{Nu}_{\mathrm{D}}} \frac{\mathrm{k}}{\mathrm{D}}=7.47 \frac{\mathrm{W}}{\mathrm{m}^{2{ }^{\circ} \mathrm{C}}}$.

Where: $\quad \mathrm{h}=$ convection heat transfer coefficient

$\overline{\mathrm{Nu}_{\mathrm{D}}}=$ Mean Seider-Tate Nusselt number wrt. the hydraulic diameter, $\mathrm{D}$

$\mathrm{k}=$ thermal conductivity of air at $100^{\circ} \mathrm{C}$

$\mathrm{D}=$ hydraulic diameter of annular region.

The details of the calculation of $\mathrm{h}$ are shown in Section A.1 of the Appendix.

Thermal Radiation

Thermal radiation boundary conditions were applied to the surfaces bounding the annular cavity of the drain tube annulus. Calculations were made for radiative heat transfer between internal surfaces and through the opening at the bottom of the annulus to an external temperature of $30^{\circ} \mathrm{C}$. Viewfactors were calculated by the MSC/THERMAL software. Emissivities, transmissivities and other parameters required for thermal radiation heat transfer were input via the template.dat.apnd file listed in Table A.1 of the Appendix.

\section{Melter Cavity Boundary Conditions}

Melter cavity boundary conditions are those applied to surfaces which bound the cavity formed by the bed (or after collapse, the pool), the walls of the melter and the refractory material which covers the top of the melter.

\section{Convection}

Convection was not considered within the cavity formed by the bed/pool, the $\mathrm{Pt} / \mathrm{Rh}$ vessel and the refractory cover. Conduction between adjacent materials was automatically calculated by MSC/THERMAL.

\section{Thermal Radiation}

Within the cavity, thermal radiation is the dominant mode of heat transfer. Because the bed and the resulting glass pool are opaque to thermal radiation, transmission need not be considered. Thermal radiation boundary conditions were applied to the surfaces bounding the cavity formed by the bed/glass pool, the walls of the Pt/Rh vessel and the refractory cover. To model the collapse of the bed, the radiation boundary conditions were modified by applying them to the exposed wall surfaces and to the top of the pool. The MSC/THERMAL software calculated viewfactors for the surfaces and utilized emissivity data from the template.dat.apnd file listed in Table A.1 of the Appendix.

\subsection{Power Distributions}

3-in CIM

The power distributions input to the model are shown in Tables 2-6. Although, square power distributions were applied for simplicity, the distributions will actually be continuous functions of axial position. 
Based on the external coil spacing and the measured temperature profile, a power distribution was estimated for the original 3-in. CIM induction coil. The power distribution was applied to the axial sections of the melter shown in Figure 3. Table 2 shows a power distribution and total power deposition in the $\mathrm{Pt} / \mathrm{Rh}$ vessel that gives the temperature profile measured for the original 3-in. CIM coil configuration. The power densities applied to the vessel in the MSC/THERMAL model are given in the table. However, it should be noted that the relationship between the temperature profile and the power distribution is not unique. That is, several power distributions may give the same temperature profile.

In order to place the maximum temperature near the top of the bed, the power distribution was modified. In the modification, the melter vessel was sectioned to concentrate power in the midsection and to reduce temperatures at the bottom of the vessel, as shown in Figure 4. Table 3 lists power densities, which locate the highest temperatures near the top of the bed when the 3in. CIM is filled with precipitate and cullet. The power densities in Table 3 correspond to the axial sectioning of Figure 2.

When the bed temperature becomes sufficiently high, it collapses into a pool of glass. Due in part to the relatively high void fraction possessed by the bed, the volume reduction is significant, approximately $79 \%$. Because the power density peaks in the midsection of the vessel, see Figure 4 and Table 3, the total power must be increased to apply sufficient heat to the pool, which occupies the lower part of the vessel. The power distribution was fixed and the total power was increased to heat the pool to approximately $1450^{\circ} \mathrm{C}$. Power densities corresponding to the increased power are shown in Table 4.



Figure 3. Sectioning of 3-in. CIM corresponding to the power distribution in Table 2. 
TABLE 2

Power Distribution to Obtain Original Temperature Distribution in the 3-Inch CIM

\begin{tabular}{|l|l}
\hline Total Power to Melter Coil & $3.16 \mathrm{~kW}$
\end{tabular}

Efficiency

Volume of Bottom

Volume of Lower Section

$55.00 \%$

Volume of Midsection

Volume of Top Section

Total Melter Pt Volume

Total Power to DT Coil

Efficiency

$1.0815 \mathrm{E}-05 \mathrm{~m}^{\wedge} 3$

$1.2988 \mathrm{E}-05 \mathrm{~m}^{\wedge} 3$

9.0737E-05 $\mathrm{m}^{\wedge} 3$

$2.4052 \mathrm{E}-05 \mathrm{~m}^{\wedge} 3$

$1.3859 \mathrm{E}-04 \mathrm{~m}^{\wedge} 3$

Drain Tube Volume

$0.28 \mathrm{~kW}$

$25.00 \%$

$2.1313 \mathrm{E}-06 \mathrm{~m}^{\wedge} 3$

Uniform Power Data

Power Density For Uniform Power

Distribution

Power Density in Drain Tube

$1.2540 \mathrm{E}+07 \mathrm{~W} / \mathrm{m}^{\wedge} 3$

3.2843E+07 W/m³

Shifted Power Distribution

\% Change From Uniform

Power to Bottom

Power to Lower Section

Power to Midsection

Power to Top Section

hange From Uniform
Power Density
$65.00 \%$
$15.00 \%$
$-27.06 \%$
$64.77 \%$

\begin{tabular}{|l|l|}
\hline & \\
& \\
& \\
& \\
& \\
& \\
& \\
Power Dens Bottom & \\
Power Dens Lower Sect & $2.0692 \mathrm{E}+07 \mathrm{~W} / \mathrm{m}^{\wedge} 3$ \\
Power Dens Mid & $1.4422 \mathrm{E}+07 \mathrm{~W} / \mathrm{m}^{\wedge} 3$ \\
Power Dens Top & $9.1468 \mathrm{E}+06 \mathrm{~W} / \mathrm{m}^{\wedge} 3$ \\
& $2.0662 \mathrm{E}+07 \mathrm{~W} / \mathrm{m}^{\wedge} 3$ \\
\hline
\end{tabular}

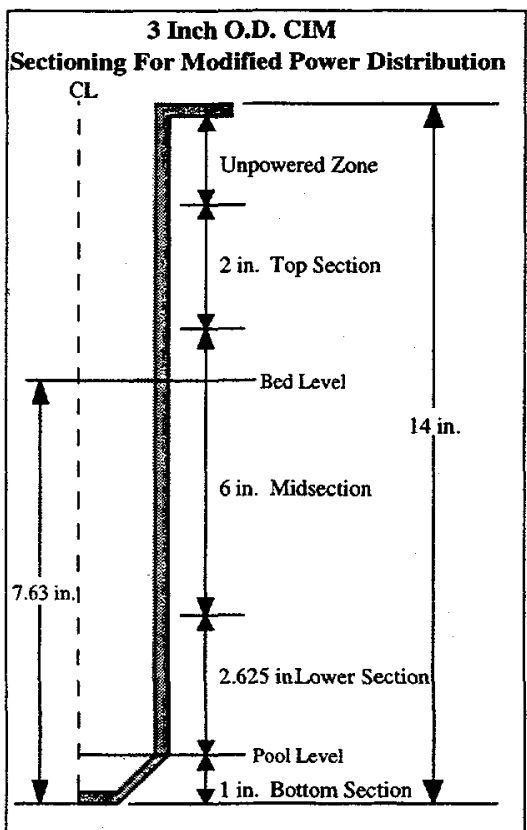

Figure 4. Sectioning of 3-in. CIM for the power distributions in Tables 3 and 4. 
TABLE 3

Power Distribution and Power Densities Which Place Maximum Temperature at Bed Surface in the 3-Inch CIM When Filled with Precipitate and Cullet

\begin{tabular}{|l|}
\hline Total Power to Melter Coil \\
Efficiency \\
Volume of Bottom \\
Volume of Lower Section \\
Volume of Midsection \\
Volume of Top Section \\
Total Melter Pt Volume \\
Total Power to DT Coil \\
Efficiency \\
Drain Tube Volume \\
Uniform Power Data \\
Power Density For Uniform Power \\
Distribution \\
Power Density in Drain Tube \\
Shifted Power Distribution \\
Power to Bottom \\
Power to Lower Section \\
Power to Midsection \\
Power to Top Section
\end{tabular}

$3.16 \mathrm{~kW}$

$1.0815 \mathrm{E}-05 \mathrm{~m}^{\wedge} 3$

$3.1568 \mathrm{E}-05 \mathrm{~m}^{\wedge} 3$

$7.2156 \mathrm{E}-05 \mathrm{~m}^{\wedge} 3$

$2.4052 \mathrm{E}-05 \mathrm{~m}^{\wedge} 3$

$1.3859 \mathrm{E}-04 \mathrm{~m}^{\wedge} 3$

$0.28 \mathrm{~kW}$

$0.10 \%$

$2.1313 \mathrm{E}-06 \mathrm{~m}^{\wedge} 3$

$1.2540 \mathrm{E}+07 \mathrm{~W} / \mathrm{m}^{\wedge} 3$

$1.3137 \mathrm{E}+05 \mathrm{~W} / \mathrm{m}^{\wedge} 3$

\% Change From Uniform

Power Density $-40.00 \%$

$-40.00 \%$

$20.00 \%$

$10.49 \%$

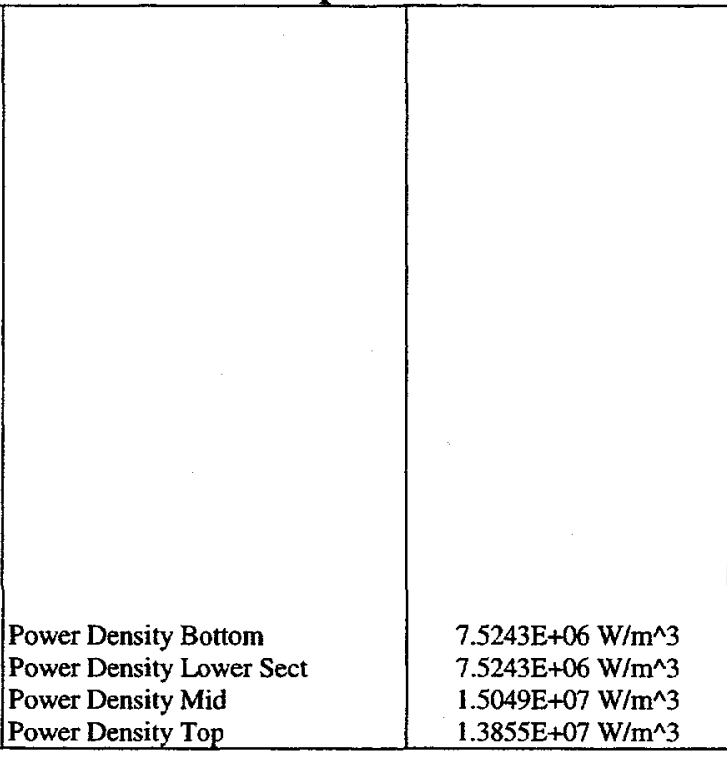

$7.5243 \mathrm{E}+06 \mathrm{~W} / \mathrm{m}^{\wedge} 3$ E $+06 \mathrm{~W} / \mathrm{m}^{\wedge}$ $1.3855 \mathrm{E}+07 \mathrm{~W} / \mathrm{m}^{\wedge} 3$

TABLE 4

Power Distribution and Power Densities Which Place Maximum Temperature at Bed Surface in the 3-Inch CIM When Bed Collapses to Pool

\begin{tabular}{|l|c|c|}
\hline Total Power to Melter Coil & $4.16 \mathrm{~kW}$ & \\
Efficiency & $55.00 \%$ & \\
Volume of Bottom & $1.0815 \mathrm{E}-05 \mathrm{~m}^{\wedge} 3$ \\
Volume of Lower Section & $3.1568 \mathrm{E}-05 \mathrm{~m}^{\wedge} 3$ \\
Volume of Midsection & $7.2156 \mathrm{E}-05 \mathrm{~m}^{\wedge} 3$ \\
Volume of Top Section & $2.4052 \mathrm{E}-05 \mathrm{~m}^{\wedge} 3$ \\
Total Melter Pt Volume & $1.3859 \mathrm{E}-04 \mathrm{~m}^{\wedge} 3$ & \\
& $0.28 \mathrm{~kW}$ & \\
Total Power to DT Coil & $0.10 \%$ & \\
Efficiency & $2.1313 \mathrm{E}-06 \mathrm{~m}^{\wedge} 3$ & \\
Drain Tube Volume & & \\
& $1.6509 \mathrm{E}+07 \mathrm{~W} / \mathrm{m}^{\wedge} 3$ & \\
Uniform Power Data & & \\
Power Density For Uniform Power & $1.3137 \mathrm{E}+05 \mathrm{~W} / \mathrm{m}^{\wedge} 3$ & \\
Distribution & & \\
Power Density in Drain Tube & Change From Uniform & \\
Shifted Power Distribution & Power Density & \\
Power to Bottom & $-40.00 \%$ & \\
Power to Lower Section & $-40.00 \%$ & Power Dens Bottom \\
Power to Midsection & $20.00 \%$ & Power Dens Lower Sect \\
Power to Top Section & $10.49 \%$ & Power Dens Mid \\
\hline
\end{tabular}

\section{5-in CIM}

The axial sectioning used for the 5-in. CIM is shown in Figure 3. The power distribution and power densities applied when the CIM is filled with precipitate and slurry are given in Table 5. 


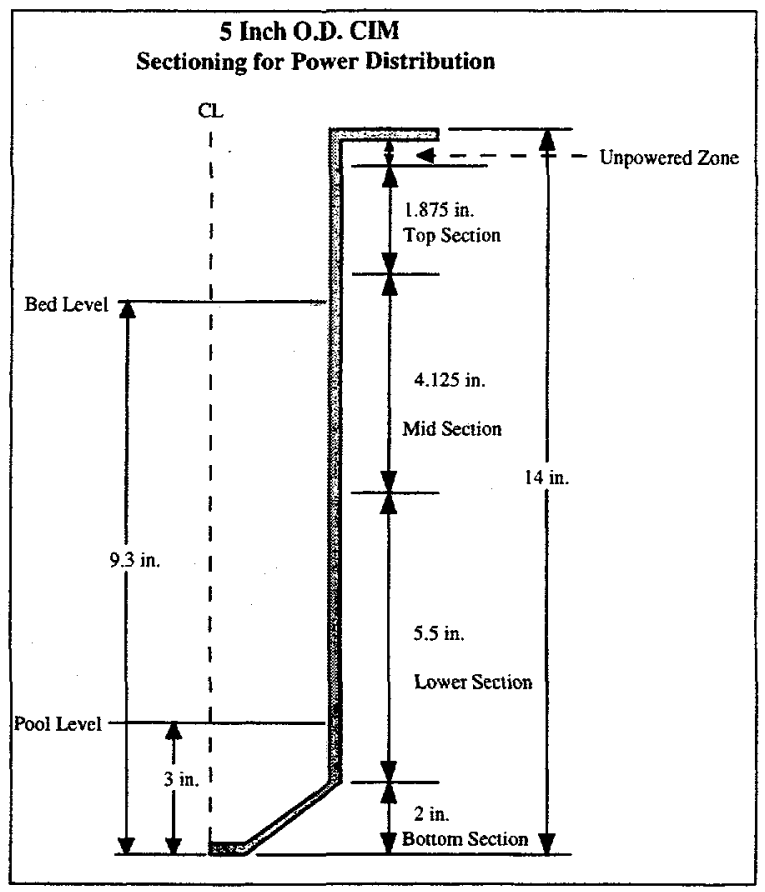

Figure 5. Sectioning of 5-in. CIM for the power distributions in Tables 5 and 6.

TABLE 5

Power Distribution and Power Densities Which Place Maximum Temperature at Bed Surface in the 5-Inch CIM When Filled with Precipitate and Cullet

\begin{tabular}{|l|}
\hline Total Power to Melter Coil \\
Efficiency \\
Volume of Bottom \\
Volume of Lower Section \\
Volume of Midsection \\
Volume of Top Section \\
Total Melter Pt Volume \\
Total Power to DT Coil \\
Efficiency \\
Drain Tube Volume \\
Uniform Power Data \\
Power Density For Uniform Power \\
Distribution \\
Power Density in Drain Tube \\
Shifted Power Distribution \\
Power to Bottom \\
Power to Lower Section \\
Power to Top Section
\end{tabular}
$3.10 \mathrm{~kW}$

$100.00 \%$

$2.8894 \mathrm{E}-05 \mathrm{~m}^{\wedge} 3$

$1.1145 \mathrm{E}-04 \mathrm{~m}^{\wedge} 3$

$8.3585 \mathrm{E}-05 \mathrm{~m}^{\wedge} 3$

3.7993E-05 $\mathrm{m}^{\wedge} 3$

2.6192E-04 $\mathrm{m}^{\wedge} 3$

$0.28 \mathrm{~kW}$

$25.00 \%$

2.1313E-06 $\mathrm{m}^{\wedge} 3$

$1.1836 \mathrm{E}+07 \mathrm{~W} / \mathrm{m}^{\wedge} 3$

$3.2843 \mathrm{E}+07 \mathrm{~W} / \mathrm{m}^{\wedge} 3$

\% Change From Uniform

Power Density

$-25.00 \%$

$-40.00 \%$

$40.00 \%$

$48.35 \%$

Power Dens Bottom

Power Dens Lower Sect

Power Dens Mid

Power Dens Top
$8.8768 \mathrm{E}+06 \mathrm{~W} / \mathrm{m}^{\wedge} 3$

$7.1014 \mathrm{E}+06 \mathrm{~W} / \mathrm{m}^{\wedge} 3$

$1.6570 \mathrm{E}+07 \mathrm{~W} / \mathrm{m}^{\wedge} 3$

$1.7558 \mathrm{E}+07 \mathrm{~W} / \mathrm{m}^{\wedge} 3$ 
When the bed collapsed to a pool, the power distribution was fixed, but the total power was increased to heat the pool to approximately $1450^{\circ} \mathrm{C}$. The power densities and total power applied to the vessel after the bed collapsed to a pool are shown in Table 6.

\section{Bare Steel 5-in CIM}

The power distribution for the bare 304L stainless steel CIM, supplied to Ameritherm, is the same as for the 5-in. CIM. The axial sectioning is therefore that shown in Figure 5 and the power densities are those in Table 5.

\section{TABLE 6}

Power Distribution and Power Densities Which Place Maximum Temperature at Bed Surface in the 5-Inch CIM When Bed Collapses to Pool

\begin{tabular}{|c|c|c|c|}
\hline Total Power to Melter Coil & $4.00 \mathrm{~kW}$ & & \\
\hline Efficiency & $100.00 \%$ & & \\
\hline Volume of Bottom & $2.8894 \mathrm{E}-05 \mathrm{~m}^{\wedge} 3$ & & \\
\hline Volume of Lower Section & $1.1145 \mathrm{E}-04 \mathrm{~m}^{\wedge} 3$ & & \\
\hline Volume of Midsection & $8.3585 \mathrm{E}-05 \mathrm{~m}^{\wedge} 3$ & & \\
\hline Volume of Top Section & $3.7993 \mathrm{E}-05 \mathrm{~m}^{\wedge} 3$ & & \\
\hline Total Melter Pt Volume & $2.6192 \mathrm{E}-04 \mathrm{~m}^{\wedge} 3$ & & \\
\hline Total Power to DT Coil & $0.28 \mathrm{~kW}$ & & \\
\hline Efficiency & $25.00 \%$ & & \\
\hline Drain Tube Volume & $2.1313 \mathrm{E}-06 \mathrm{~m}^{\wedge} 3$ & & \\
\hline Uniform Power Data & & & \\
\hline $\begin{array}{l}\text { Power Density For Uniform Power } \\
\text { Distribution }\end{array}$ & $1.5272 \mathrm{E}+07 \mathrm{~W} / \mathrm{m}^{\wedge} 3$ & & \\
\hline Power Density in Drain Tube & $3.2843 \mathrm{E}+07 \mathrm{~W} / \mathrm{m}^{\wedge} 3$ & & \\
\hline Shifted Power Distribution & $\begin{array}{c}\text { \% Change From Uniform } \\
\text { Power Density }\end{array}$ & & \\
\hline Power to Bottom & $-25.00 \%$ & Power Dens Bottom & $1.1454 \mathrm{E}+07 \mathrm{~W} / \mathrm{m}^{\wedge} 3$ \\
\hline Power to Lower Section & $-40.00 \%$ & Power Dens Lower Sect & $9.1631 \mathrm{E}+06 \mathrm{~W} / \mathrm{m}^{\wedge} 3$ \\
\hline Power to Midsection & $40.00 \%$ & Power Dens Mid & $2.1381 \mathrm{E}+07 \mathrm{~W} / \mathrm{m}^{\wedge} 3$ \\
\hline Power to Top Section & $48.35 \%$ & Power Dens Top & $2.2655 \mathrm{E}+07 \mathrm{~W} / \mathrm{m}^{\wedge} 3$ \\
\hline
\end{tabular}

\section{RESULTS}

For cases in which the 3 and 5-in. CIM's contained a bed of cullet and oxalate precipitate, temperature profiles were calculated when maximum bed temperatures exceeded $1350^{\circ} \mathrm{C}$.

During the heating process the bed height varied, hence, an approximate value was used in the models. In order to place maximum temperatures near the top of the bed, the power distribution was shifted upward. When the bed collapses to a pool, the high power zones in the melter wall are uncovered and not in direct contact with the glass. Therefore, calculations were performed to estimate wall temperatures when the glass pool is maintained at temperatures near $1450^{\circ} \mathrm{C}$ prior to pouring. Pool calculations were performed for both the 3 and 5-in. CIM's. For the use of Ameritherm, Inc. in coil design, the temperature distribution in an empty, uninsulated 5-in. CIM, composed of 304L stainless steel was calculated at the target power distribution. 


\subsection{3-in CIM}

\section{Comparison Between Model and Experiment}

Temperature measurements shown in Table 7 were obtained from experimental tests with the original 3-in. CIM for the coil configuration designed for the Pu vitrification program.

Elevations listed in the table were relative to the bottom of the CIM. T1A, T1B and T1C were thermocouples welded to the wall of the vessel at different elevations. Sensor T1D was a thermocouple which was inserted into the bed/pool and located approximately $0.5 \mathrm{in}$. from the vertical side wall and $1 \mathrm{in}$. above the bottom of the CIM. Sensor T1E was an optical pyrometer and was aimed near the juncture of the sloped bottom and the vertical wall of the CIM, taking readings from the outer wall at 1.5 to $1 \mathrm{in}$. above the bottom of the CIM.

\section{TABLE 7}

Experimental Data for the 3-in CIM With Original Coil Configuration

\begin{tabular}{|c|c|c|c|c|}
\hline Sensor & $\begin{array}{c}\text { Axial Elevation Above } \\
\text { Bottom of Melter }\end{array}$ & Run 3 & Run 4 & Run 5 \\
\hline T1A & 8.5 in & $1018^{\circ} \mathrm{C}$ & $1040^{\circ} \mathrm{C}$ & $1010^{\circ} \mathrm{C}$ \\
\hline T1B & 6 in & $1139^{\circ} \mathrm{C}$ & $1165^{\circ} \mathrm{C}$ & $1072^{\circ} \mathrm{C}$ \\
\hline T1C & 3.5 in & $1268^{\circ} \mathrm{C}$ & $1285^{\circ} \mathrm{C}$ & $1212^{\circ} \mathrm{C}$ \\
\hline T1D & 1 in & $1446^{\circ} \mathrm{C}$ & $1444^{\circ} \mathrm{C}$ & $1426^{\circ} \mathrm{C}$ \\
\hline T1E & $1.5-1$ in & $1375^{\circ} \mathrm{C}$ & $1378^{\circ} \mathrm{C}$ & $1338^{\circ} \mathrm{C}$ \\
\hline
\end{tabular}

Due to imperfect transfer of energy within the induction system, losses occur. The DC power is the power supplied to the induction system. The percentage of the DC power that is supplied to the vessel is the system efficiency. To assess the ability of the model to reproduce experimental results, the power distribution was modified for a DC power of $3.16 \mathrm{~kW}$ at $55 \%$ efficiency. When the power distribution of Table 2 with the axial sectioning shown in Figure 3 was applied, the model calculated the temperature distribution shown in Figures 6 and 7. 


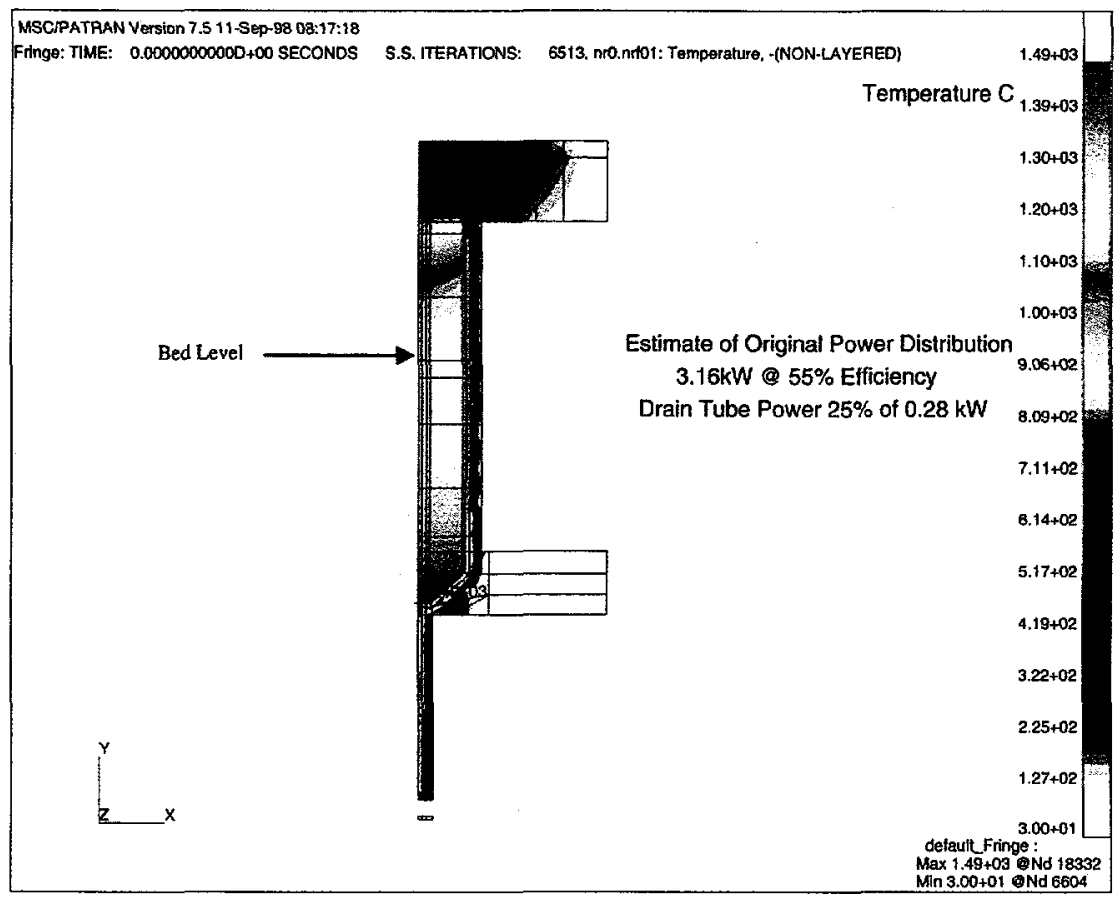

Figure 6. Temperature distribution for the 3-in CIM corresponding to an approximation of the original power profile.

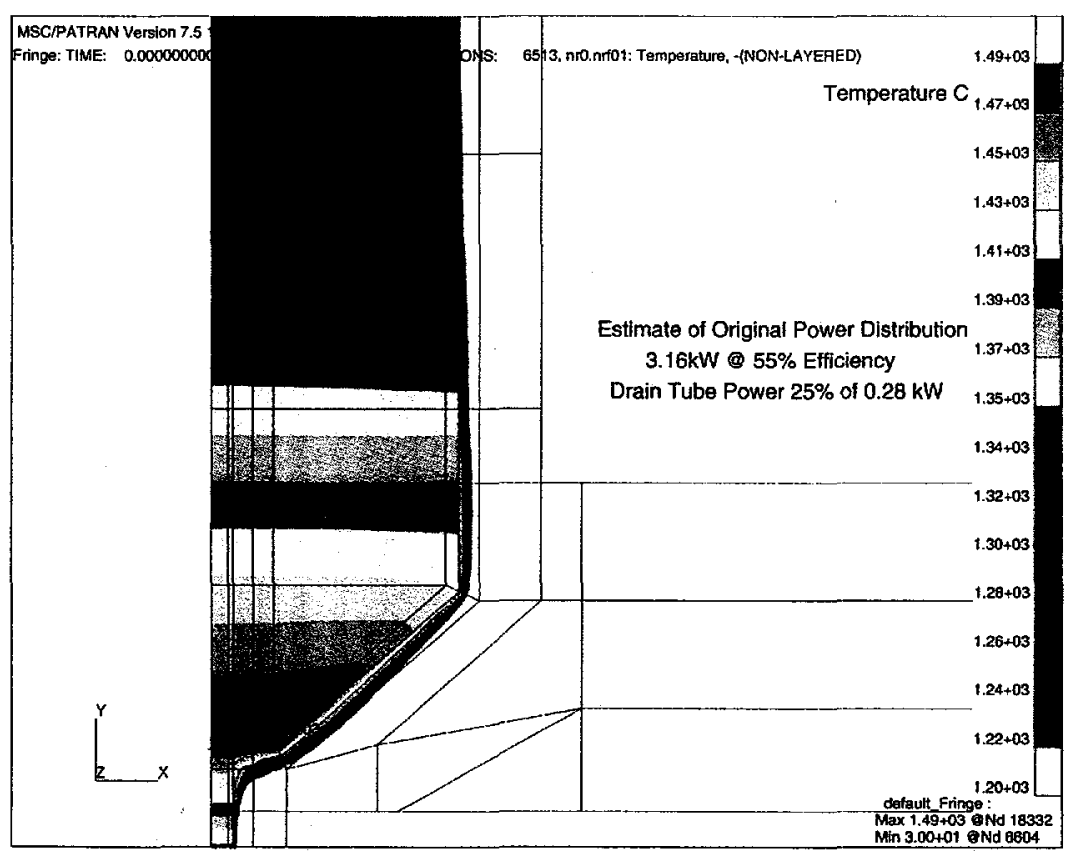

Figure 7. Zoom view for Figure 6, showing bottom of 3-in CIM. 
The predicted temperatures shown in Figures 6 and 7 agree well with the data in Table 7. The favorable comparison suggests that the assumed power distribution approximates that which actually existed in the 3-in CIM for the original coil configuration. From Table 2, it can be seen that the power distribution is heavily peaked toward the bottom of the melter, resulting in higher temperatures there. The axial spacing between coil loops corresponds reasonably well to the proportional differences in the power distribution. Although the relationship between the power distribution and the temperature profile is not unique, the favorable comparison between calculations and data, along with the coil spacing, suggest that the power density is much higher near the bottom of the melter. Because the power distribution is not expected to change significantly during heat-up, the highest temperatures in the melter would remain at the bottom as the power is increased.

\section{Modified Power Distribution}

Melter Containing Bed

In order to place the maximum temperatures near the surface of the bed, the power distribution was modified as shown in Table 3, with axial sectioning shown in Figure 4. In this case, the melter contained a 7.5 in deep bed of precipitate and cullet. The temperature profile calculated for this power distribution is shown in Figure 8.



Figure 8. Upward shifted power distribution for the 3-in CIM, containing 7.5 in of precipitate and cullet. 
From Figure 8, it can be seen that the bed temperature is maximized near the top and is approximately $200^{\circ} \mathrm{C}$ lower at the bottom of the melter.

\section{Bed Collapsed to Pool}

As the bed melts, it collapses to a pool. From experimental data, it was found that the pool depth in the 3-in. CIM was approximately $1 \mathrm{in.}$ The constitutive properties of the pool are those of 50 SrABS glass. Figure 9 shows the predicted temperature profile obtained by maintaining the power density distribution of Table 3 and replacing the 7.5 in. bed with a 1 in deep glass pool. From the figure, it can be seen that the pool temperature was calculated to be approximately $1100^{\circ} \mathrm{C}$, which is too cool to pour.



Figure 9. Upward shifted power distribution for the 3-in CIM, with bed collapsed to a 1 in deep pool at same power as the 7.5 in. deep bed.

In order to achieve a sufficiently high pool temperature, the total power was increased from 3.16 $\mathrm{kW}$ to $4.16 \mathrm{~kW}$ while maintaining the same power distribution and efficiency. The power densities are listed in Table 4 and, as for the bed, the axial sectioning is shown in Figure 4. The resulting temperature profile is shown in Figure 10. 


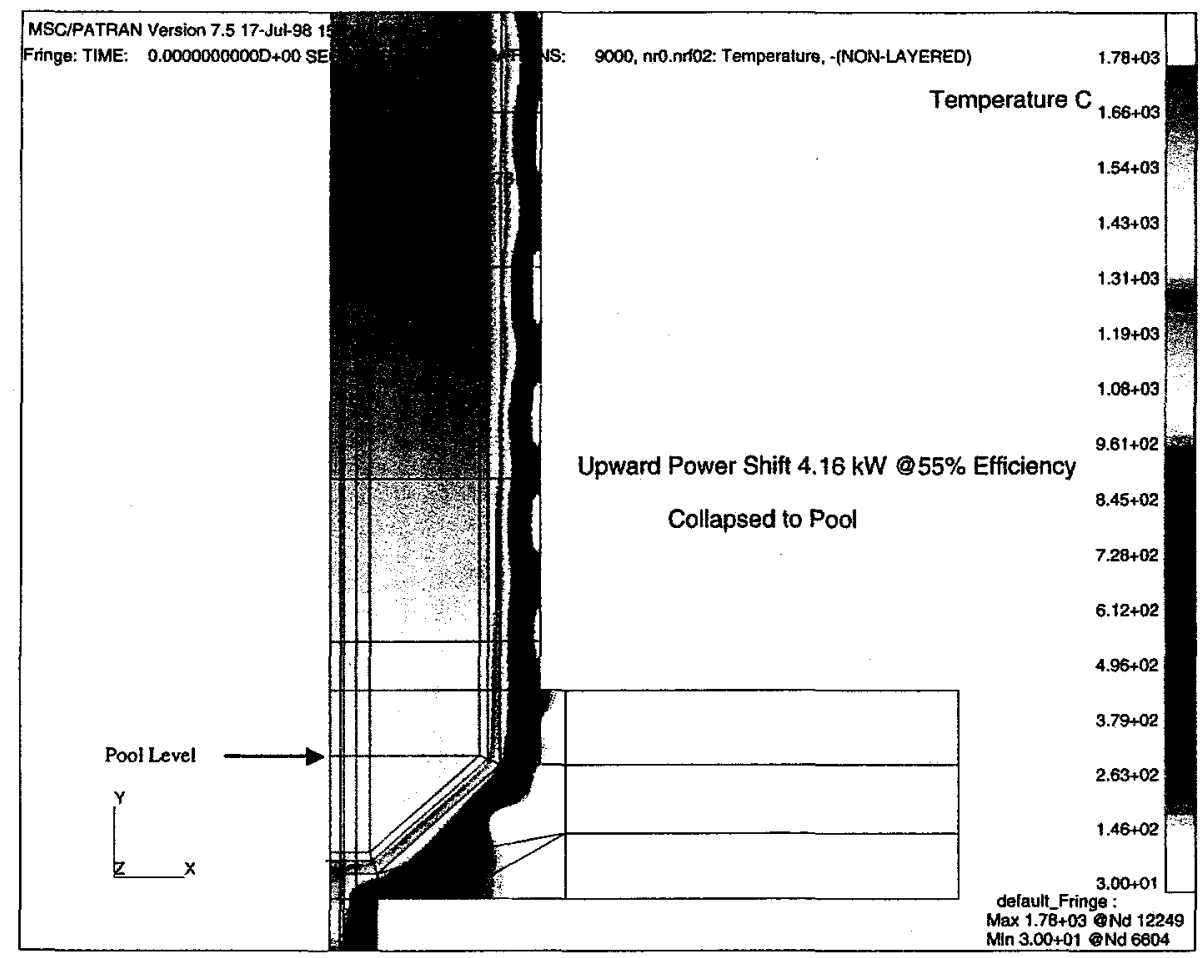

Figure 10. Upward power temperature distribution for the 3-in CIM, with bed collapsed to a 1 in deep pool and increased total power.

It can be seen from Figure 10 that at the elevated power, the pool temperature is near $1450^{\circ} \mathrm{C}$, which is sufficiently high for pouring. However, for a fixed power distribution at this total power, the maximum wall temperature is nearly $1800^{\circ} \mathrm{C}$. At $1800^{\circ} \mathrm{C}$ the $80 / 20 \mathrm{Pt} / \mathrm{Rh}$ alloy is near its melting point and beyond the limit for structural integrity. Other power distributions may exist that do not require such high wall temperatures to heat the pool after the bed collapses. However, the results of the calculation suggest that the power distribution may need to be changed as the bed collapses to a pool. A shift in power distribution during the heating of the melter may be most easily accomplished by placing an independent induction coil about the tapered lower section of the melter. By adjusting the relative power between the coil about the cylindrical section and the coil about the tapered bottom, the temperature distribution could be varied.

\subsection{5-in CIM \\ Melter Containing Bed}

In order to place the maximum temperatures near the surface of the bed, the power distribution of Table 5 together with the axial sectioning of Figure 5 was applied to the 5-in. CIM. The temperature profile for the case in which the CIM contains a 9.2 in. deep bed of oxalate precipitate and cullet is shown in Figure 11. From the figure, it can be seen that the maximum bed temperature is located at the top of the bed and that the temperature decreases by approximately $200^{\circ} \mathrm{C}$ as the bottom of the melter is approached. 


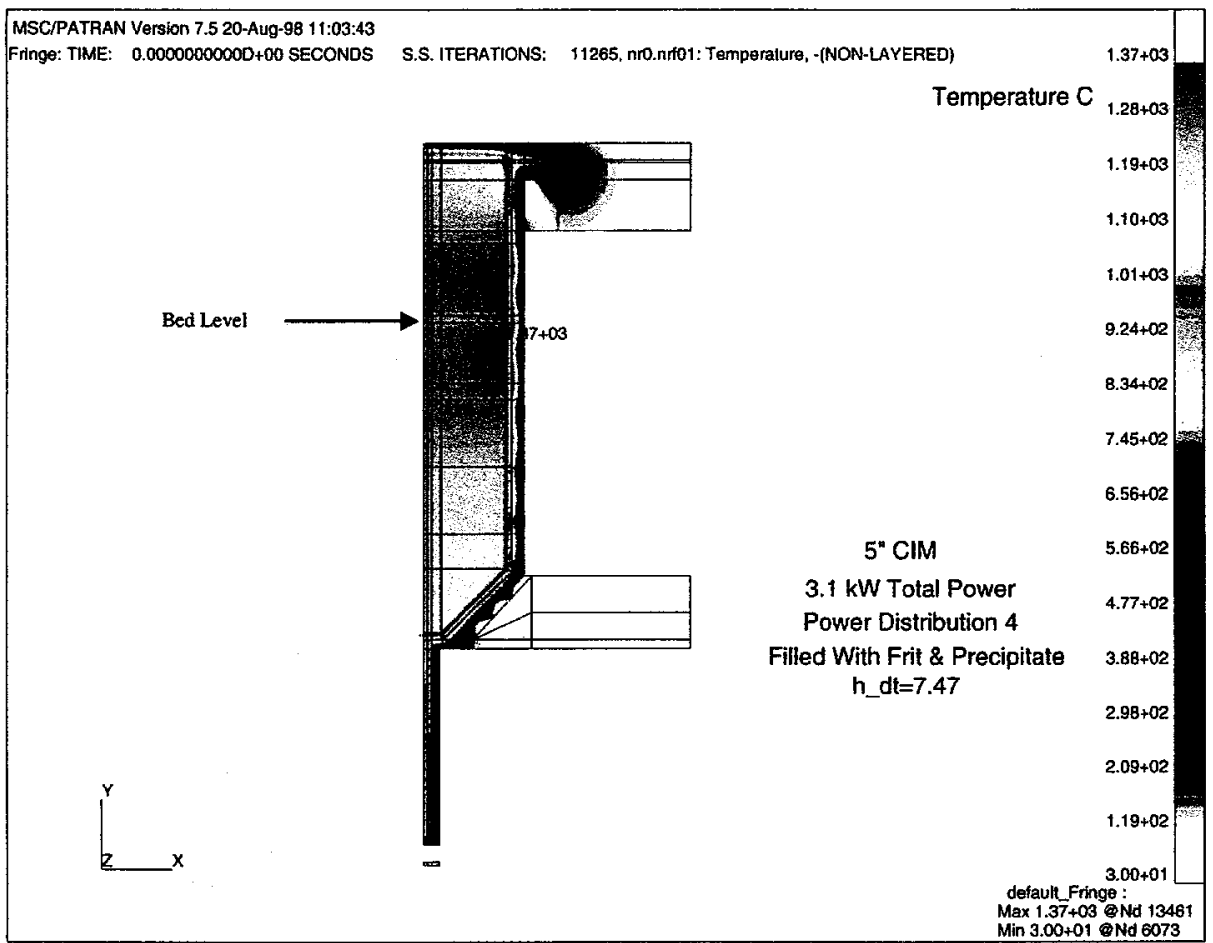

Figure 11. Temperature distribution for the 5-in CIM, with a 9.2 in deep bed of precipitate and cullet.

\section{Bed Collapsed to Pool}

Experiments with the 3-in. CIM showed that after melting, the glass pool occupies a volume that is approximately $79 \%$ less than the initial bed volume. Therefore, given the dimensions of the 5in. CIM, the 9.2 in. deep bed will collapse to a pool that is approximately 3 in. deep. Due to the change in material level as the bed collapses, it was necessary to examine the maximum wall temperature when the pool was raised to temperatures near $1450^{\circ} \mathrm{C}$ for pouring. To model the pool, the internal properties and wall boundary conditions were modified and the total power supplied to the melter was increased, resulting in the power densities shown in Table 6 . Because the power distribution was assumed to remain unchanged, the axial sectioning shown in Figure 5 still applies. Figure 12 shows the predicted temperature profile in the melter. 


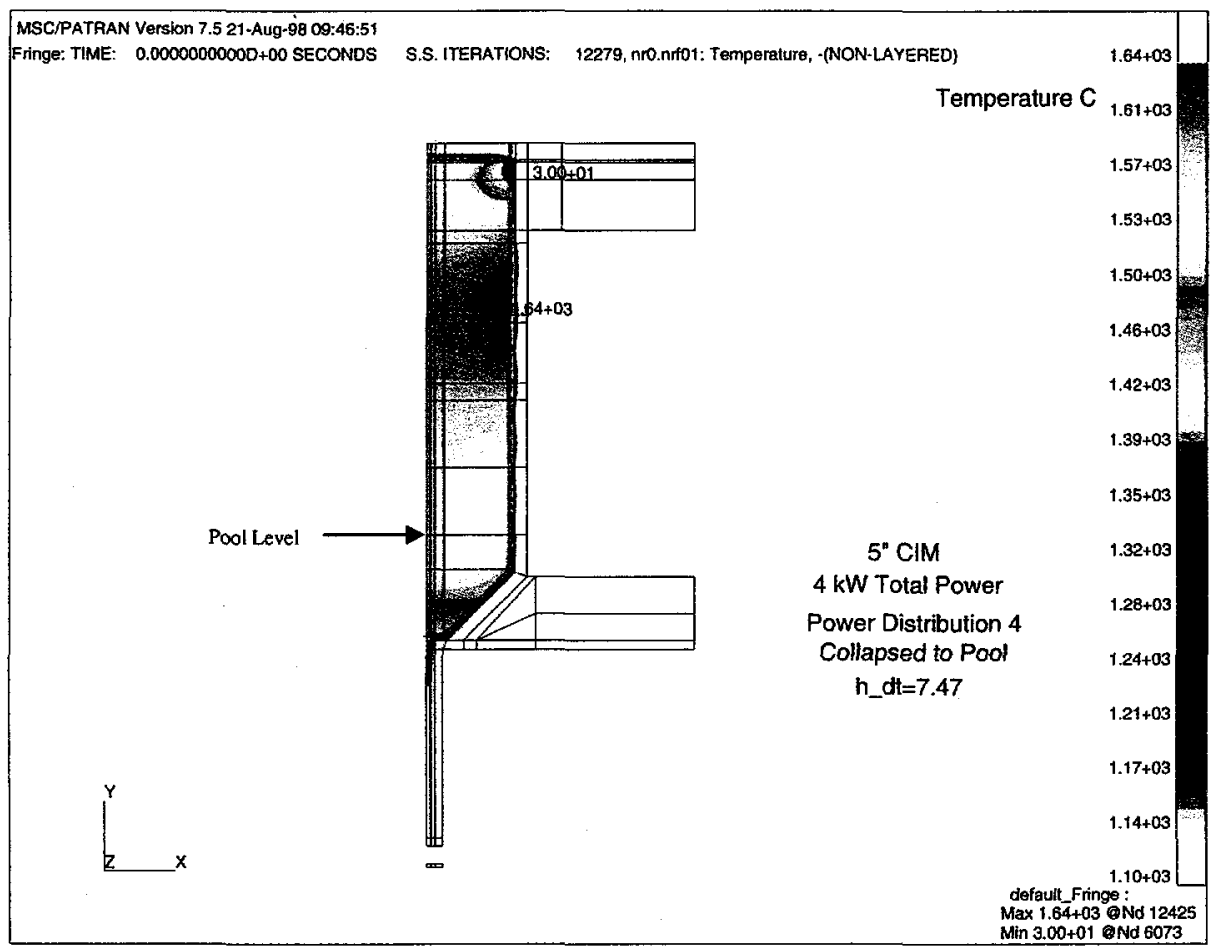

Figure 12. Temperature distribution for the 5-in CIM, with the bed collapsed to a 3 in. deep pool and increased total power.

From Figure 12, it can be seen that when the pool is at an acceptable temperature for pouring, the maximum wall temperature would be approximately $1640^{\circ} \mathrm{C}$. Although this is marginally acceptable, it would still be advisable to have the ability to shift the power distribution as the bed collapses to a pool.

\subsection{Bare Steel 5-in CIM}

The vendor for induction heating equipment, Ameritherm, Inc. was contracted to fabricate induction coils that would produce the power distribution in Table 5. Ameritherm can not accurately calculate the power distribution induced by a coil and requires a workpiece to test the coil design. Therefore, they were supplied with an uninsulated 5-in. vessel fabricated from 304L stainless steel. If the 304L vessel had the same power distribution as that in Figure 11, it would not be expected to have the same temperature distribution because it is uninsulated and empty. It is, however, tacitly assumed that the $304 \mathrm{~L}$ CIM couples inductively in the same way as a Pt/Rh alloy vessel of the same dimensions. The assumption implies that for the same coil configuration, the same power densities are produced in both the Pt/Rh alloy vessel and the 304L vessel. While Ameritherm could not accurately estimate the power distribution for a given coil geometry, measurements of the melter surface temperature could easily be made. Therefore, the temperature profile corresponding to the power distribution of Table 5 was calculated for the empty, uninsulated 5-in 304L CIM, see Figure 13. By adjusting the coil geometry to achieve the 
calculated temperature distribution, the power distribution of Table 5 (with axial sectioning given by Figure 5) could be approached.



Figure 13. Temperature distribution for an empty, uninsulated 5-in CIM fabricated from 304L stainless steel, with power distribution from Table 5. Note that the vessel is on its side in the Figure.

\section{CONCLUSIONS}

The power distribution in the melter and consequently the temperature profile in the bed of precipitate and glass formers is determined by the geometric configuration of the induction coils. By inputting the power distribution to the thermal model for the CIM, the corresponding temperature profile can be calculated. The power distribution was manipulated to give the desired temperature profile, locating the maximum temperature near the top of the bed. By designing induction coils that approximate the target power distribution, the desired temperature profile may be obtained. The induction coil vendor, Ameritherm, Inc., was supplied with an uninsulated, empty, 304L CIM and a temperature profile for the target power distribution, to tune their coil design. If the inductive coupling between the $304 \mathrm{~L}$ vessel and the $\mathrm{Pt} / \mathrm{Rh}$ vessel is the same, a given coil configuration will produce the same power distribution in both vessels.

In an effort to validate the model, the power distribution and the overall efficiency (fraction of the DC power to the power supply to be transferred to the vessel) were adjusted until the experimentally observed temperature profile in the 3-in. CIM was obtained, see Table 2 and Figure 3. In the comparison, it was found that the overall efficiency at the assumed power 
distribution was approximately 55\%. Although the relationship between the power distribution and the temperature profile is not unique, the coil spacing supported the assumed power distribution.

In the 3-in CIM the maximum temperature was placed near the top of the bed by shifting the power distribution upwards, see Table 3 and Figure 4 . However, when the bed collapsed to a pool and was heated to $1450^{\circ} \mathrm{C}$ for this power distribution, very high wall temperatures were predicted. From Figure 10, it can be seen that the wall temperature would need to be nearly $1800^{\circ} \mathrm{C}$ to raise the pool temperature to $1450^{\circ} \mathrm{C}$. High wall temperatures result when heating the pool because the maximum power is located at a high position on the wall. The mode of heat transfer inside the vessel changes from conduction to thermal radiation as the walls become exposed when the bed collapses. It may be possible to find a power distribution that does not produce such high wall temperatures when the glass pool temperature is raised to $1450^{\circ} \mathrm{C}$. However, the calculation suggests that it may be necessary to change the shape of the power distribution as the melter is heated. A change in the shape of the distribution could be implemented by placing an independent coil about the tapered base of the melter.

For the 5-in. CIM, it was found that the power distribution, which placed the maximum temperature near the top of the bed, produced a maximum wall temperature of $1640^{\circ} \mathrm{C}$ when the pool was heated to approximately $1450^{\circ} \mathrm{C}$. Although the wall temperature is marginally acceptable, the calculations suggest that for the 5-in CIM it might be possible to keep the power distribution fixed after the bed has collapsed. However, as with the 3-in. CIM, a separate coil located about the tapered base would permit the power distribution to be shifted when heating the melter.

When the bed of frit and precipitate collapses to a pool, the heat transfer boundary conditions on the inner wall surfaces change. Thermal radiation is the dominant mode of heat transfer in the part of the melter which is unoccupied by material. Therefore, as the wall becomes exposed, temperature changes occur locally for the uncovered surface itself and for areas optically exposed to the uncovered surface. Local temperature effects depend on the extent of change in the bed level, the geometry of the melter and the power distribution. Calculations have shown that for fixed total power and fixed power distribution, the wall temperature may either decrease or increase as the bed drops, depending on melter dimensions and the change in level.

The induction coils are water cooled and assumed to remain near $30^{\circ} \mathrm{C}$. The coils contact the outer surface of the refractory about the cylindrical section of the melter. Coils are also embedded in cast refractory material at the bottom, and for the 5-in CIM, the top of the melter. Fixed temperature boundary conditions applied at the point of contact for the induction coils and at the location of embedded coils result in a downward shift in peak temperatures in the melter, refractory and its contents.

If the bottom of the melter is too cold, glass stratification as evidenced by compositional analysis and coloration, accompanied by very large differences in viscosity, has been observed. The concentration of components of the precipitate within the glass greatly affect its viscosity and liquidus temperature. Therefore, the variation in viscosity has been attributed to the distribution 


\section{APPENDIX}

\section{A.1 CONVECTION CORRELATIONS}

\section{External Convection}

On the external surfaces of the melter, natural convection boundary conditions were applied. On the vertical sides of the melter assembly, convection was estimated through the use of the correlation

$\mathrm{Nu}=\left(0.68+\frac{0.670 \mathrm{Ra}^{0.25}}{\left[1.0+\left(\frac{0.492}{\mathrm{Pr}}\right)^{9 / 16}\right]^{4 / 9}}\right.$

or

$\mathrm{Nu}=\left(0.825+\frac{0.387 \mathrm{Ra}^{1 / 6}}{\left[1.0+\left(\frac{0.492}{\mathrm{Pr}}\right)^{9 / 16}\right]^{8 / 27}}\right)^{2}$

for isothermal plates with $\mathrm{Ra}>1.0 \times 10^{9}$,

where ${ }^{*}: \quad \mathrm{Nu}=$ Nusselt number $\equiv \frac{\mathrm{hL}}{\mathrm{k}}$

$\mathrm{k}=$ thermal conductivity

$\mathrm{h}=$ convection heat transfer coefficient

$\mathrm{L}=$ characteristic length (plate length)

$\operatorname{Pr}=\operatorname{Prandtl}$ number $\equiv \frac{v}{\alpha}$

$v=$ kinematic viscosity $\equiv \frac{\mu}{\rho}$

$\mu=$ viscosity

$\rho=$ density

$\mathrm{Ra}=$ Raleigh number $\equiv \mathrm{GrPr}$

$\mathrm{Gr}=$ Grashof number $\equiv \frac{\mathrm{g} \beta\left(\mathrm{T}_{\text {wall }}-\mathrm{T}_{\infty}\right) \mathrm{L}^{3}}{v^{2}}$

*All properties are calculated at the film temperature $\mathrm{T}_{\mathrm{f}}=\frac{\left(\mathrm{T}_{\text {wall }}+\mathrm{T}_{\infty}\right)}{2}$. 


$$
\beta=\text { volume coefficient of expansion } \equiv \frac{1}{\mathrm{~T}} ;[\mathrm{T}]=\mathrm{K}
$$

For upward facing horizontal surfaces, the model used the Nusselt number correlation $\mathrm{Nu}=0.15 \mathrm{Ra}^{1 / 2} \quad$ for isothermal plates with $1.0 \times 10^{7}<\mathrm{Ra}<3.0 \times 10^{10}$.

In the correlation of Eq. 3, $\mathrm{L}$ (in $\mathrm{Nu}=\frac{\mathrm{hL}}{\mathrm{k}}$ ) is replaced with (surface area)/(perimeter).

For downward facing horizontal surfaces, the model used the Nusselt number correlation

$\mathrm{Nu}=0.27 \mathrm{Ra}^{1 / 4} \quad$ for isothermal plates with $3.0 \times 10^{5}<\mathrm{Ra}<3.0 \times 10^{10}$

Again, in the correlation of Eq. 4, $\mathrm{L}$ (in $\mathrm{Nu}=\frac{\mathrm{hL}}{\mathrm{k}}$ ) is replaced with (surface area)/(perimeter).

\section{Convection in Drain Tube}

The volumetric flowrate of air within the drain tube annulus is $20 \mathrm{scfm}$. Therefore, the bulk velocity, $\mathrm{U}$, of the air is

$$
\mathrm{U}=\frac{\dot{\mathrm{V}}}{\mathrm{A}}=0.2837 \frac{\mathrm{m}}{\mathrm{s}},
$$

where: $\quad \dot{V}=$ volumetric flowrate of the air $=20 \mathrm{ft}^{3} / \mathrm{hr}=1.5732 \times 10^{-4} \mathrm{~m}^{3} / \mathrm{s}$

$$
\mathrm{A}=\text { cross-sectional area of the annulus }=5.5454 \times 10^{-4} \mathrm{~m}^{2} \text {. }
$$

Hence, the Reynolds number is

$$
\operatorname{Re}_{\mathrm{D}}=\frac{\mathrm{UD}}{\mathrm{v}}
$$

where: $\quad \mathrm{D}=$ hydraulic diameter $=2\left(\mathrm{r}_{\text {outer }}-\mathrm{r}_{\text {inner }}\right)=1.93 \times 10^{-2} \mathrm{~m}$

$\mathrm{r}=$ inner or outer radius of annulus

$v=$ kinematic viscosity of air at $100^{\circ} \mathrm{C} \approx 23.0 \times 10^{-6} \mathrm{~m}^{2} / \mathrm{s}$.

For the above parameters, $\operatorname{Re}_{\mathrm{D}}=238$ and the flow in the annulus is laminar.

The forced convection heat transfer coefficient in the air annulus of the drain tube is approximated with the Seider-Tate correlation for laminar tube flow ${ }^{3}$. In the approximation, the bulk air temperature is set at $100^{\circ} \mathrm{C}$, the mean tube temperature is set at $400^{\circ} \mathrm{C}$ and the hydraulic 
diameter of the annulus is used in place of the tube diameter. The correlation for the mean Seider-Tate Nusselt number, $\overline{\mathrm{Nu}_{\mathrm{D}}}$, over a tube of length, $\mathrm{L}$, is

$$
\overline{N u_{D}}=1.86\left(\frac{\operatorname{Re}_{D} \operatorname{PrD}}{L}\right)^{1 / 3}\left(\frac{\mu}{\mu_{w}}\right)^{0.14},
$$

where: $\quad \mu_{\mathrm{w}}=$ air viscosity (at $100^{\circ} \mathrm{C}$ ) $\approx 2.0 \times 10^{-5} \mathrm{~Pa}-\mathrm{s}$

$\mu_{\mathrm{w}}=$ air viscosity at wall $\left(\right.$ at $\left.400^{\circ} \mathrm{C}\right) \approx 3.2 \times 10^{-5} \mathrm{~Pa}-\mathrm{s}$

$\mathrm{L}=$ drain tube length $=0.1524 \mathrm{~m}$.

Therefore, for the above parameter values

$\overline{\mathrm{Nu}_{\mathrm{D}}}=4.81$.

The convection heat transfer coefficient for the drain tube annulus, with $\mathrm{k}_{\mathrm{air}}=$ (thermal conductivity of air at $100^{\circ} \mathrm{C} \approx 0.03 \mathrm{~W} / \mathrm{m}^{\circ} \mathrm{C}$ ), is then approximated as

$$
\mathrm{h}=\overline{\mathrm{Nu}_{\mathrm{D}}} \frac{\mathrm{k}}{\mathrm{D}}=7.47 \frac{\mathrm{W}}{\mathrm{m}^{20} \mathrm{C}} .
$$




\section{A.2 MSC/THERMAL DATA FILE}

\section{Thermal Radiation and Convection Data Contained in the template.dat.apnd File}




GP\# 5

0.064

0.064

0.0

MPID\#I

MPID\#2

MPID\#3

3

9.8

1

2

MPID\#4 MPID\#5

*

*\#\#\#\#\#\#\#\#\#\#\#\#\#\#\#\#\# TOP UNDERSIDE \#\#\#\#\#\#\#\#\#\#\#\#\#\#\#\#\#

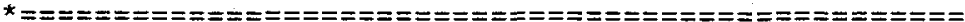

* TID CFIG Supplied Supplied

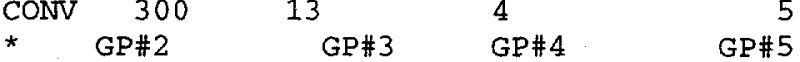
0.0508
0.0508
$-90.0$

* MPID\# 1

MPID\#2

MPID\#4

$$
2
$$

$$
3
$$

4

5

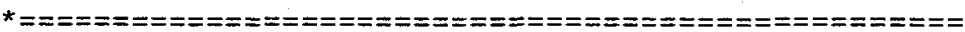

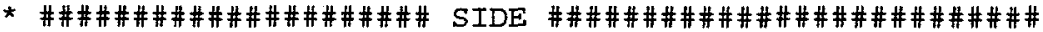

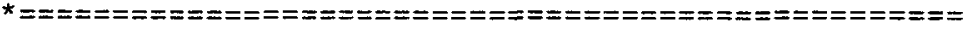

$\begin{array}{cccc}\text { TID } & \text { CFIG } & \text { Supplied } & \text { Supplied } \\ 400 & 13 & 4 & 5\end{array}$

GPH 2

0.2635

13

GP\#3 GP\#4 GP\# 5

$\begin{array}{lll}0.2635 & 0.0 & 9.8\end{array}$

MPID\#1

MPID\#3 MPID\#4 MPID\#5

2

4

5

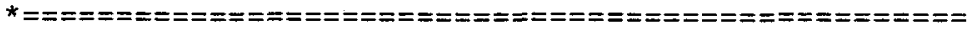

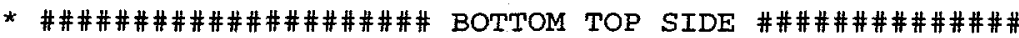



* No. of GP's No. of MPID's

* TID CFIG Supplied Supplied

CONV $500 \quad 13 \quad 4 \quad 5$

* GP\#2 GP\#3 GP\#4 GP\# 5

$\begin{array}{llrr}0.0508 & 0.0508 & 90.0 & 9.8\end{array}$

* MPID\#1 MPID\#2 MPID\#3 MPID\#4 MPID\#5

2

3

4

5



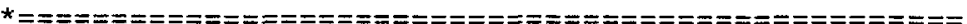

* No. of GP's No. of MPID's

* TID CFIG Supplied Supplied

CONV $600 \quad 13 \quad 4 \quad 5$

* GP\#2 GP\#3 GP\#4 GP\#5

$\begin{array}{llll}0.0508 & 0.0508 & 0.0 & 9.8\end{array}$

* MPID\#1 MPID\#2 MPID\#3 MPID\#4 MPID\#5

$12 \quad 2 \quad 3 \quad 4 \quad 5$

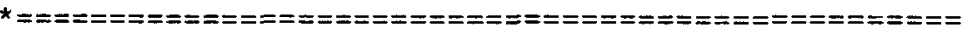

* \#\#\#\#\#\#\#\#\#\#\#\#\#\#\#\#\#\#\# BOTTOM UNDER SIDE \#\#\#\#\#\#\#\#\#\#\#\#\#

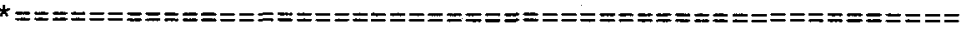

CONV $\begin{array}{llll}700 & 13 & 4 & 5\end{array}$

* GP\#2

0.0705

GP\#3

0.0705

GP\#4

GP\#5

MPID\#1

1

MPID\#2 MPID\#3 MPID\#4 MPID\#5

$-90.0$ 




